\title{
Neurografía por resonancia magnética: Aspectos técnicos y aplicaciones clínicas
}

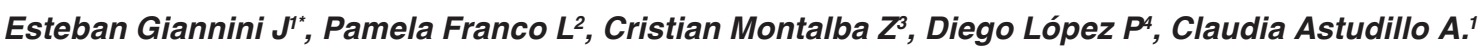

1. Radiólogo Musculoesquelético. Departamento de diagnóstico por imágenes. Clínica Las Condes. Santiago, Chile.

2. Magister en Físico Médico. Centro de Imágenes Biomédicas, Pontificia Universidad Católica de Chile, Santiago, Chile.

3. Tecnólogo Médico. Centro de Imágenes Biomédicas. Pontificia Universidad Católica de Chile, Santiago, Chile.

4. Tecnólogo Médico. Departamento de diagnóstico por imágenes. Clínica Las Condes. Santiago, Chile.

Magnetic resonance neurography: Technical aspects and clinical applications

\section{Resumen:}

La evaluación del nervio periférico en resonancia magnética (RM) puede ser un desafío, es más, un número significativo de lesiones pueden pasar desapercibidas cuando se utilizan protocolos convencionales. En los últimos años ha aumentado la disponibilidad de secuencias selectivas al nervio. Cada una de estas herramientas tiene requisitos técnicos y artefactos específicos que deben ser conocidos para evitar errores diagnósticos. El presente artículo de revisión tiene como objetivo discutir los avances de la neurografía por resonancia magnética (NRM) mediante la aplicación de técnicas isotrópicas, funcionales -como difusión (DWI) e imágenes con tensor de difusión (DTI)-, supresión de grasa y flujo sanguíneo, con énfasis en protocolos de adquisición, dificultades técnicas y aplicaciones clínicas.

Palabras clave: Difusión (DWI); Imágenes con tensor de difusión (DTI); Nervio; Neurografía; Neurografía por resonancia magnética.

\begin{abstract}
:
The evaluation of the peripheral nerve in magnetic resonance imaging (MRI) can be challenging, furthermore, a significant number of injuries can be unseen when using classic protocols. In recent years, the availability of selective nerve sequences has increased. Each of these sequences has specific technical requirements and artifacts that must be known to avoid diagnostic errors. The purpose of this article is to review the advances in magnetic resonance neurography (NRM) protocol by applying isotropic, functional techniques -such as diffusion (DWI) and images with diffusion tensor (DTI)-, fat suppression and blood flow, with emphasis in acquisition protocols, technical difficulties and clinical applications.
\end{abstract}

Keywords: Diffusion tensor imaging (DTI); Diffusion-weighted imaging (DWI); Magnetic resonance neurography; Nerve neurography.

Giannini E, et al. Neurografía por resonancia magnética: Aspectos técnicos y aplicaciones clínicas. Rev Chil Radiol 2021; 27(2): 88-103.

${ }^{*}$ Correspondencia: Esteban Giannini Jara / estebangiannini@gmail.com

Trabajo enviado el 07 de abril de 2020. Aceptado para publicación el 08 de marzo de 2021. 


\section{Introducción}

La evaluación de las lesiones en nervios periféricos habitualmente se basa en una profunda anamnesis, examen físico y test electrodiagnósticos. La distribución anatómica, progresión temporal y propiedades electrofisiológicas de las neuropatías en la mayoría de los casos es suficiente para determinar la etiología y severidad del daño nervioso'. Sin embargo, los estudios electrofisiológicos no proveen información anatómica ni espacial sobre el nervio o de las estructuras que lo rodean, lo cual puede ayudar a determinar la causa de la neuropatía.

La visualización directa del nervio y su entorno, principalmente con ultrasonido (US) y resonancia magnética (RM), permite confirmar la presencia de atrapamiento y compresión, identificando la etiología de la neuropatía ${ }^{2}$, lo cual es especialmente útil en presentaciones clínicas atípicas o cuando los estudios electrofisiológicos son equívocos o contradictorios ${ }^{3}$.

EI US se caracteriza por ser un examen de bajo costo, accesible, no invasivo, permite visualizar largos segmentos del nervio en poco tiempo, además se puede realizar una evaluación dinámica e incluso reproducir la sintomatología (signo de Tinnel ecográfico). Sin embargo, es un estudio operador dependiente y no es útil en nervios profundos.

La RM ofrece una mejor representación de los nervios más profundos y una mayor resolución espacial y de contraste de los tejidos blandos ${ }^{4}$. Además, permite caracterizar no solo al nervio sino también su entorno, identificando signos de miopatía por denervación dentro de las primeras 24-48 horas después de la lesión nerviosa ${ }^{5}$.

El término "neurografía por resonancia magnética (NRM)" fue utilizado por primera vez en 1992 por
Howe et al, para describir la aplicación de secuencias difusión (DWI) con supresión grasa para delimitar los nervios periféricos de los tejidos circundantes ${ }^{6}$. El término actualmente incluye cualquier combinación de técnicas cualitativas o cuantitativas para evaluar la patología del nervio periférico.

El propósito de esta revisión es responder las preguntas más frecuentes al planificar, realizar e interpretar la NRM. Discutiremos las características fisiológicas y patológicas del nervio periférico que determinan su representación en RM, abordando los principales avances técnicos y radiológicos descritos en el último tiempo, con principal énfasis en el estudio de plexo braquial y lumbar.

\section{Sección A: La estructura interna del nervio y su señal en resonancia magnética}

A. Pregunta 1a. ¿Cómo es la estructura interna del nervio?

El sistema nervioso periférico es una estructura delicada y muy sensible a cambios en su microambiente, por lo que tiene varias medidas de protección para limitar la influencia externa.

Los axones están ubicados en el espacio endoneural, el cual presenta además líquido endoneural y vasos endoneurales. Cada axón es rodeado por células de Schwann que forman una vaina con o sin mielina. Varios axones forman un fascículo rodeado por perineuro. El perineuro y sus proyecciones al endoneuro constituyen la principal barrera de difusión entre el endoneuro y los tejidos extrafasciculares (barrera perineural). Finalmente, varios fascículos y el nervio están rodeados por el epineuro, que es una extensión de la duramadre que otorga resistencia a la tracción pero no forma barreras ${ }^{7}$ (Figura 1A).

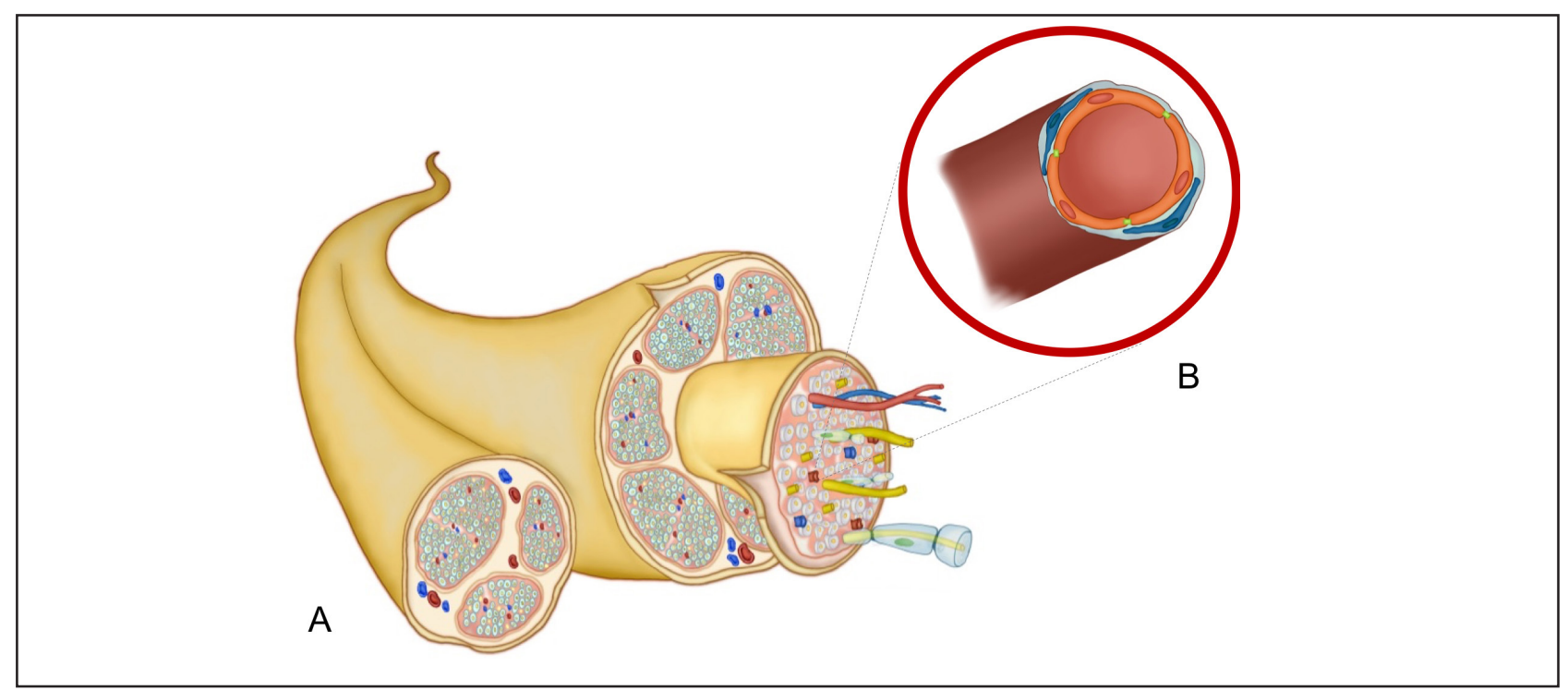

Figura 1: (A) Esquema de un nervio periférico: Cada fascículo nervioso está formado por múltiples axones y pequeños vasos sanguíneos, todos rodeados por perineuro. El conjunto de fascículos es rodeado por el epineuro. (B) Esquema de un vaso endoneural. La barrera hematoneural está formada por células endoteliales, pericitos, sus respectivas membranas basales y uniones estrechas entre células endoteliales y entre pericitos. 
La homeostasis del microambiente endoneural es mantenida por la barrera hematoneural (BHN), equivalente a la barrera hematoencefálica del sistema nervioso central. La BHN está ubicada en la pared de los vasos endoneurales, formada principalmente por células endoteliales, pericitos, sus respectivas membranas basales e importantes uniones estrechas entre células endoteliales y entre pericitos ${ }^{7}$ (Figura 1B).

A. Pregunta 1b. ¿Cómo afecta la estructura del nervio en su representación en RM?

Los nervios presentan varias particularidades que tienen repercusión en su representación en RM, las que podemos utilizar a nuestro favor. Son estructuras largas que atraviesan varias regiones corporales susceptibles a campos magnéticos heterogéneos. Están ubicados dentro del paquete neurovascular donde la señal de la grasa y vasos sanguíneos pueden resultar un problema si no se manejan adecuadamente. La organización en múltiples fascículos ordenados puede determinar artefactos como lo es el efecto de ángulo mágico. Además, la mielina que cubre los axones junto a otros factores restringe la difusión de las moléculas de agua, propiedad que es utilizada en técnicas como difusión y tractografías.

A. Pregunta 1c. ¿Cómo es la señal de un nervio normal y patológico en RM?

Los nervios son levemente hiperintensos en T2 debido a la presencia de líquido endoneural, hallazgo más evidente cuando hay sustracción de la señal grasa. Aún más, numerosas neuropatías de etiología traumática, compresiva e inflamatoria traen consigo un aumento del contenido de agua en los nervios, por lo que aumenta su señal ${ }^{8}$ (Figura 2). Para potenciar la alteración de señal T2 se recomienda tiempo de eco (TE) largo de aproximadamente 90-130 ms, lo cual ayuda a disminuir el efecto de ángulo mágico ${ }^{9}$.

Por otro lado, la potenciación T1 permite evaluar de mejor manera la anatomía del nervio periférico, la grasa intraneural, perineural, el engrosamiento epineural y la separación entre el nervio y una eventual masa o fibrosis focal. Además, por excelencia es la secuencia que permite evaluar atrofia muscular ${ }^{10}$, caracterizada por infiltración grasa y disminución de volumen muscular, factor que otorga importante valor pronóstico ${ }^{11,12}$.

\section{A. Pregunta 1d. En neuropatía periférica traumática} ¿Cómo se clasifica la severidad del daño nervioso?

La severidad del daño nervioso es importante porque se correlaciona con el potencial de recuperación y necesidad de cirugía ${ }^{13}$. Si el cuerpo celular se mantiene intacto, el axón lesionado puede regenerarse a partir del cabo axonal proximal, lo cual depende de la integridad de las estructuras de soporte. Es por ello que la severidad del daño habitualmente se clasifica en base al daño estimado de las distintas capas de tejido conectivo (Figura 3). Existen varias clasificaciones, siendo las más usadas las clasificaciones de Seddon y Sunderland (Tabla 1).

A. Pregunta 1e. Imágenes de nervio postcontraste. ¿Cómo afecta la presencia de barrera hematoneural en la utilización de medio de contraste paramagnético basado en gadolinio?

El nervio normalmente no realza con gadolinio debido a la presencia de la BHN, por lo que no se recomienda su uso en un estudio de una neuropatía de etiología traumática o atrapamiento ya que no aporta mayor información ${ }^{9}$. Si es útil cuando se sospecha alteración de esta barrera, en casos de masa perineural o intraneural, o bien una polineuropatía como linfoma, amiloidosis, neuropatías desmielinizantes o neuropatías hereditarias.

\section{Sección B: Planos anatómicos de visualización}

B. Pregunta 1a. Considerando el trayecto curvo de los nervios, ¿Cómo podemos mejorar su visualización en planos ortogonales?

En los estudios de plexopatías resulta difícil el seguimiento de los nervios periféricos debido a su compleja anatomía curva. Se han publicado protocolos con uso de planos 2D oblicuos con la finalidad de capturar el segmento más largo del nervio en cada imagen. Sin embargo, en este tipo de adquisiciones las referencias anatómicas se pierden, lo que dificulta su interpretación y seguimiento ${ }^{14}$.

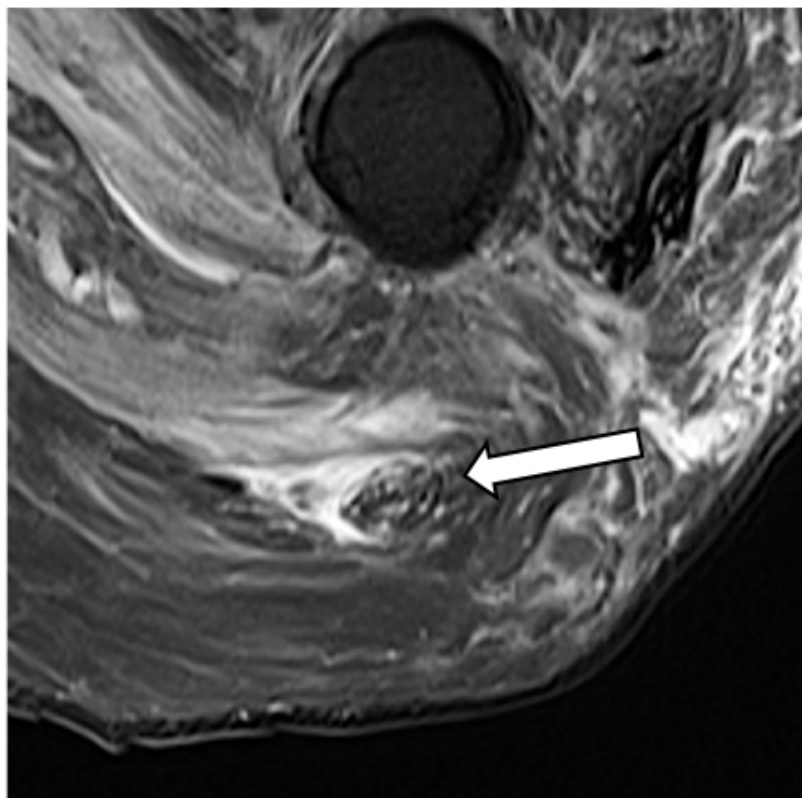

Figura 2: Neuritis infecciosa del nervio ciático izquierdo en paciente con artritis séptica. DP axial con saturación espectral de la grasa muestra engrosamiento del nervio ciático (flecha) con edema intra y perineural. 

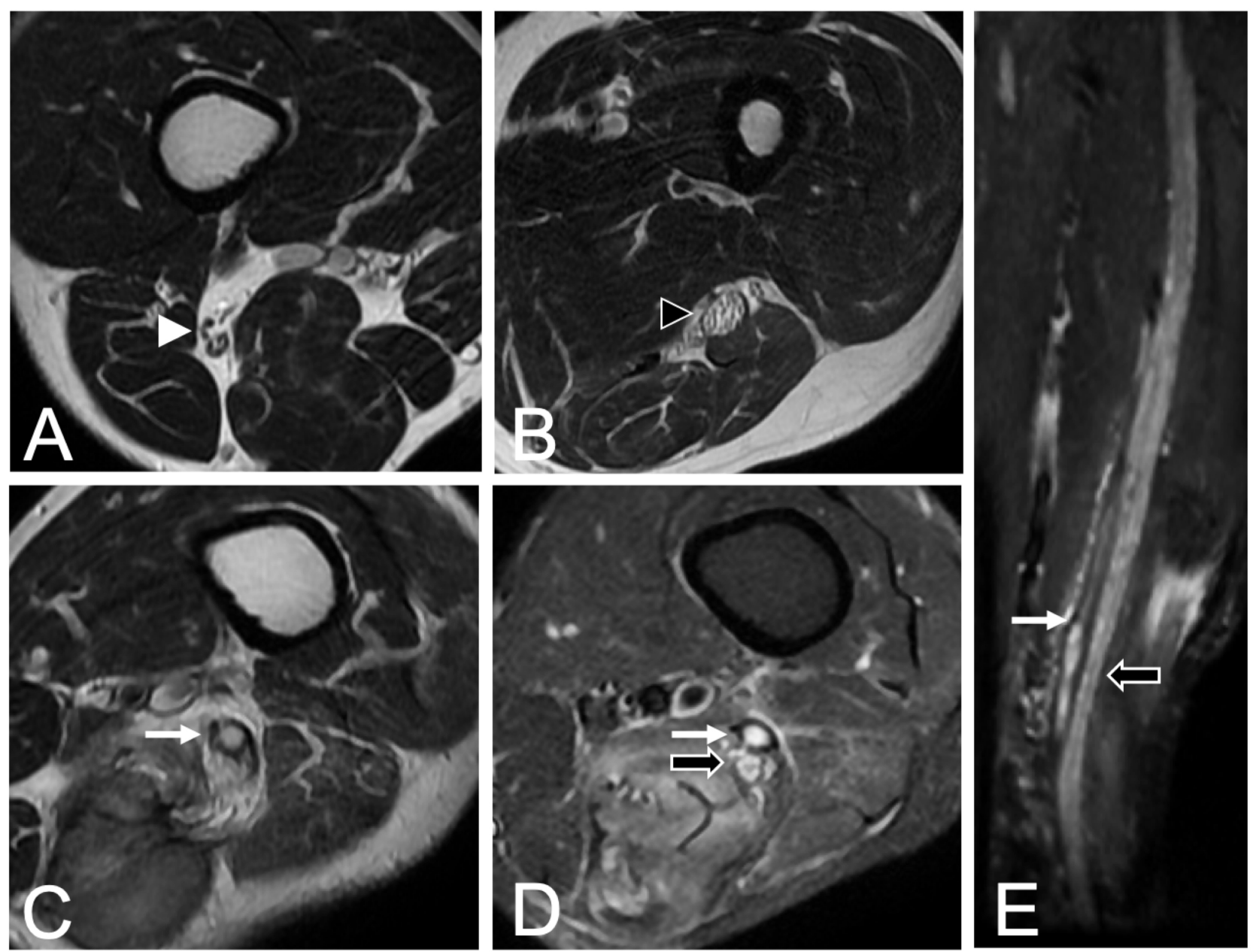

Figura 3: Lesión traumática del nervio ciático izquierdo proximal a la bifurcación. (A) Imagen comparativa del nervio ciático derecho (asintomático). (B) Nervio ciático izquierdo (sintomático) marcadamente engrosado y con edema intraneural. (C), (D) y (E) Lesión de alto grado del componente peroneo común izquierdo (flecha blanca) con rotura axonal, endoneural y perineural, solo con epineuro intacto (Sunderland IV) mientras el componente tibial (flecha negra) presenta lesión grado II.

En relación a lo anterior, se recomienda el uso de planos 3D isotrópicos, los cuales permiten reconstrucciones multiplanares, ya sea en el plano perpendicular al nervio para poder evaluar su patrón fascicular o bien reconstrucciones curvilíneas para la visualización confiable del eje longitudinal del nervio, que puede tener un papel determinante en la definición de la localización y etiología de la compresión ${ }^{15}$ (Figura 4).

\section{B. Pregunta 1b. ¿En qué consisten las secuencias} $3 D$ Isotrópicas?

El término isotrópico alude a la adquisición de una imagen en la cual el valor del pixel y del voxel posee la misma resolución en cada dimensión, por ejemplo $0,6 \times 0,6 \times 0,6 \mathrm{~mm}^{3}$, lo que permite reconstrucciones $3 \mathrm{D}$ de la misma resolución en cualquier plano deseado. Además, carece de separación entre los cortes y limita la interferencia entre ellos, lo que puede disminuir la relación señal-ruido ${ }^{9}$. Otras ventajas son una menor sensibilidad a las inhomogeneidades del campo magnético principal $\left(B_{0}\right)$ y una gran cobertura espacial dentro de un tiempo de adquisición razonable (aproximadamente 6 minutos) ${ }^{16}$.

Su principal desventaja es que cualquier movimiento durante la adquisición se propaga a todo el volumen y puede degradar la imagen significativamente. En una adquisición 2D solo el corte que se adquirió cuando se movía el paciente es el que se ve afectado.

\section{B. Pregunta 1c. ¿Qué secuencias 3D isotrópicas} hay disponibles? ¿Cuáles son sus características?

Existen diversas opciones según el fabricante, tales como: "Cube" (GE), "Volume ISotropic Turbo spin echo Acquisition" (VISTA, Philips), "isoFSE" 
Tabla 1. Clasificación de neuropatía traumática.

\begin{tabular}{|c|c|c|c|c|c|}
\hline $\begin{array}{l}\text { Clasificación } \\
\text { Seddon }\end{array}$ & $\begin{array}{l}\text { Clasificación } \\
\text { Sunderland }\end{array}$ & Descripción & RM & $\begin{array}{l}\text { Historia } \\
\text { natural }\end{array}$ & Manejo \\
\hline Neuropraxia & $\begin{array}{l}\text { Primer } \\
\text { grado }\end{array}$ & $\begin{array}{l}\text { Desmielinización segmentaria } \\
\text { con alteración en la conducción } \\
\text { nerviosa. Axones y capas de } \\
\text { tejido conectivo intactos }\end{array}$ & $\begin{array}{l}\text { Leve aumento } \\
\text { de señal T2. }\end{array}$ & $\begin{array}{l}\text { Recuperación } \\
\text { probable, } \\
\text { mediada por } \\
\text { la reparación } \\
\text { de las células } \\
\text { gliales. }\end{array}$ & Conservador \\
\hline \multirow[t]{3}{*}{ Axonotmesis } & $\begin{array}{l}\text { Segundo } \\
\text { grado }\end{array}$ & $\begin{array}{l}\text { Rotura axonal, con endoneuro, } \\
\text { perineuro y epineuro intactos }\end{array}$ & $\begin{array}{l}\text { Engrosamiento } \\
\text { difuso del nervio } \\
(<50 \%) \text { con alta } \\
\text { señal T2 y } \\
\text { cambios } \\
\text { miopáticos de } \\
\text { denervación. }\end{array}$ & $\begin{array}{l}\text { La recuperación } \\
\text { es probable pero } \\
\text { prolongada } \\
\text { debido a la } \\
\text { degeneración } \\
\text { walleriana }\end{array}$ & Conservador \\
\hline & $\begin{array}{l}\text { Tercer } \\
\text { grado }\end{array}$ & $\begin{array}{l}\text { Rotura axonal y endoneural, } \\
\text { con perineuro y epineuro } \\
\text { intactos }\end{array}$ & $\begin{array}{l}\text { Engrosamiento } \\
\text { difuso del nervio } \\
\text { (>50\%) con alta } \\
\text { señal T2 y mayores } \\
\text { cambios miopáticos } \\
\text { de denervación. }\end{array}$ & $\begin{array}{l}\text { La regeneración } \\
\text { se ve limitada } \\
\text { por una } \\
\text { fibrosis leve; } \\
\text { la recuperación } \\
\text { es probable con } \\
\text { déficits leves }\end{array}$ & Conservador \\
\hline & $\begin{array}{l}\text { Cuarto } \\
\text { grado }\end{array}$ & $\begin{array}{l}\text { Rotura axonal, endoneural } \\
\text { y perineural, con epineuro } \\
\text { intacto }\end{array}$ & $\begin{array}{l}\text { Nervio engrosado, } \\
\text { con alta señal T2 } \\
\text { y discontinuidad } \\
\text { fascicular. }\end{array}$ & $\begin{array}{l}\text { La regeneración } \\
\text { se ve limitada } \\
\text { por fibrosis } \\
\text { moderada a grave; } \\
\text { la recuperación } \\
\text { es poco probable, } \\
\text { con graves } \\
\text { déficits }\end{array}$ & $\begin{array}{l}\text { Considerar } \\
\text { cirugía }\end{array}$ \\
\hline \multirow[t]{2}{*}{ Neurotmesis } & $\begin{array}{l}\text { Quinto } \\
\text { grado }\end{array}$ & Rotura completa del nervio. & $\begin{array}{l}\text { Discontinuidad } \\
\text { completa del nervio. } \\
\text { El gap puede ser } \\
\text { ocupado por } \\
\text { hemorragia o tejido } \\
\text { fibroso. }\end{array}$ & $\begin{array}{l}\text { Sin posibilidad } \\
\text { de recuperación } \\
\text { espontánea; } \\
\text { formación de } \\
\text { neuromas }\end{array}$ & $\begin{array}{l}\text { Considerar } \\
\text { cirugía }\end{array}$ \\
\hline & $\begin{array}{l}\text { Sexto } \\
\text { grado }\end{array}$ & $\begin{array}{l}\text { Cualquier combinación de } \\
\text { lesiones de primer a quinto grado }\end{array}$ & & & $\begin{array}{l}\text { Considerar } \\
\text { cirugía }\end{array}$ \\
\hline
\end{tabular}
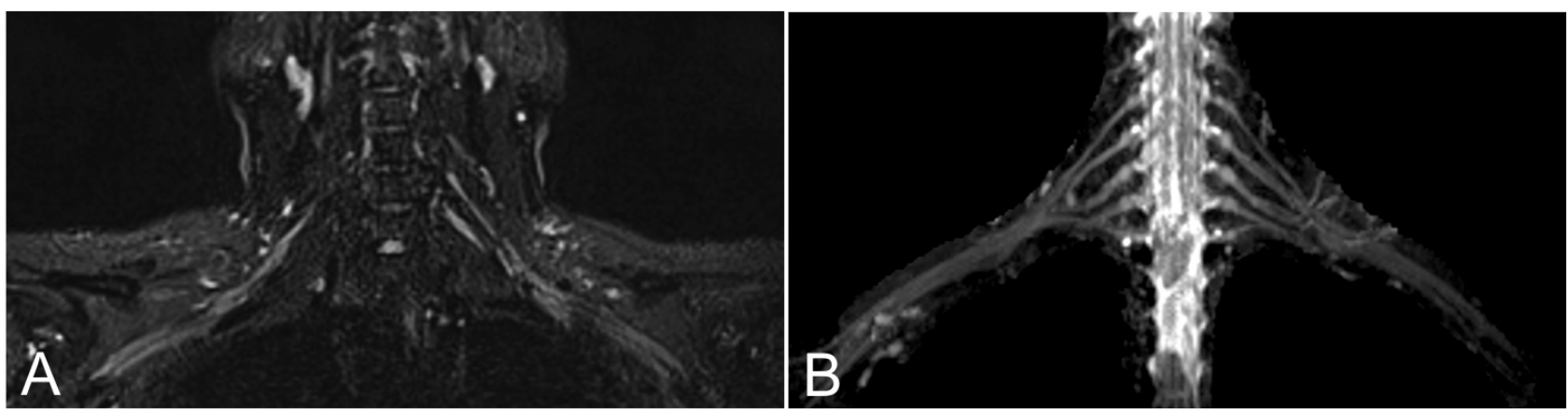

Figura 4: Plexo braquial. (A) STIR coronal isotrópico con compensación de flujo. (B) Reconstrucción de la misma imagen con proyección de máxima intensidad (MIP). 
(Hitachi), "3D MVOX" (Canon) y "Sampling Perfection with Application optimized Contrasts using different flip angle Evolution" (SPACE, Siemens).

Si bien la implementación precisa varía según el proveedor, presentan ciertas características en común. Corresponden a una variante de la secuencia Turbo Spin Eco (TSE) que permite un gran Eco Train Length (ETL) entre 100-250 ecos. Además, a diferencia de la secuencia TSE convencional en que el pulso de refase es constante de $180^{\circ}$, el ETL de las secuencias $3 \mathrm{D}$ consiste en ángulos de inclinación de pulso variables menores a $180^{\circ}$, para reducir el desenfoque y aumento de temperatura de los tejidos ${ }^{17}$.

Las imágenes 3D isotrópicas pueden ser potenciadas en T1, T2 o Densidad Protónica (DP) y permiten co-aplicar técnicas para suprimir la señal de la grasa y flujo sanguíneo.

\section{B. Pregunta 2. Existen secuencias 3D isotrópicas} para la evaluación de raíces nerviosas en el segmento preganglionar ¿Cuáles son sus características?

Para la evaluación de las raíces nerviosas en el segmento preganglionar se utilizan las denominadas Secuencias Mielográficas, que corresponden a Secuencias 3D isotrópicas con alto peso T2 (Figura 5).

Se caracterizan por un alto contraste entre el líquido cefalorraquídeo y las raíces nerviosas, poseyendo una excelente resolución espacial (grosor de corte 0,6-1 $\mathrm{mm}$, reconstruido cada $0,3-0,6 \mathrm{~mm})^{18}$. Permiten la evaluación precisa de raíces nerviosas en segmento preganglionar y detección de pseudomeningoceles en caso de rotura o avulsión. Se deben adquirir en contexto de trauma ya que permite una mayor precisión diagnóstica ${ }^{19}$.
Sin embargo, hay que tener en consideración la obtención del artefacto de flujo, que puede determinar falso positivo de avulsión.

Secuencias de este tipo según el proveedor incluyen: "Constructive Interference in the Steady State" (CISS, Siemens), "3D True Fast Imaging with the Steady State Precession" (TrueFISP, Siemens), "Fast Imaging Employing Steady State Acquisition" (FIESTA, GE), "Driven Equilibrium" (DRIVE, Philips) ${ }^{16}$.

\section{Sección C: Parámetros técnicos}

C. Pregunta 1. Resonador magnético: ¿Cuál Teslaje es preferible?

La NRM es habitualmente realizada en resonadores con un teslaje de 1,5 T o 3T. En general se prefieren resonadores de $3 \mathrm{~T}$ porque poseen varias ventajas en comparación a los de 1,5 T, como mayor relación señal-ruido (Signal-to-Noise ratio, SNR), mayor resolución espacial y contraste ${ }^{20}$, lo que permite, entre otras cosas, una mejor visualización del patrón fascicular del nervio en imágenes axiales y una mayor sensibilidad a la restricción a la difusión en secuencias DWI (Figura 6).

Sus principales desventajas son una mayor tasa de absorción específica (Specific Absorption Rate, SAR), mayor heterogeneidad del campo magnético principal $\left(\mathrm{B}_{0}\right)$ y local $\left(\mathrm{B}_{1}\right)$, mayor efecto de susceptibilidad magnética y mayor desplazamiento químico entre la grasa y agua ${ }^{21}$.

Es importante considerar que en imágenes en $3 T$ el tiempo de relajación T1 es más largo mientras el tiempo de relajación T2 se acorta levemente, por lo que no es posible traspasar protocolos de 3T a 1,5 $\mathrm{T}$ sin modificar ciertos parámetros.

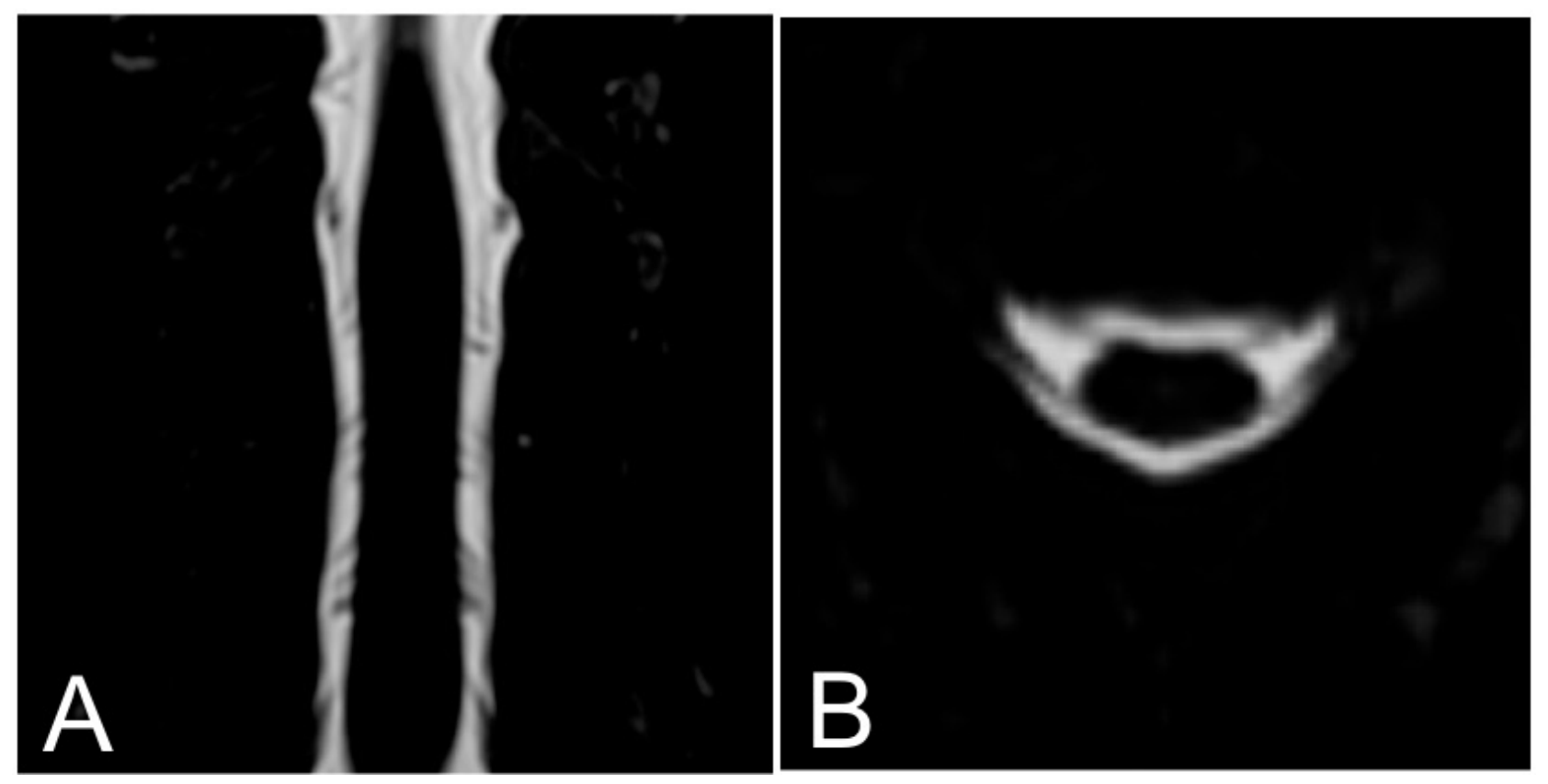

Figura 5: Secuencia mielográfica en columna cervical. (A) Adquisición coronal y (B) reconstrucción axial. Muestra la anatomía intradural que incluye raíces ventrales y dorsales de los nervios espinales. 
En el caso particular de pacientes con implantes metálicos (compatibles con RM), en que el hardware se ubica dentro del Field Of View (FOV), se prefiere un campo magnético de 1,5 $\mathrm{T}$.

C. Pregunta 2. ¿Qué parámetros técnicos podemos mejorar para optimizar nuestro estudio?

Las imágenes deben ser adquiridas con alta resolución, con matriz de al menos 256 × 256 píxeles (resolución en el plano de 0,3-0,4 $\mathrm{mm}^{2}$ ) con poco espaciado de eco para evitar el desenfoque ${ }^{22}$.

El grosor de corte recomendado para extremidades distales de 2-3 $\mathrm{mm}$ y en extremidades proximales y plexo de 4-5 mm. La separación entre los cortes debe ser menor o igual a $10 \%$ del grosor de corte ${ }^{23}$.

El FOV se debe mantener lo más pequeño posible para mantener imágenes de alta resolución. Es útil que los pacientes se realicen el estudio electrofisiológico o ecográfico antes que la NRM para acotar el sitio anatómico de interés. También se recomienda una adquisición previa con FOV grande que permita visualizar ambos lados del paciente y poder garantizar un estudio comparativo entre el lado sintomático y asintomático (Figura 7).

\section{Sección D. Neurografía por difusión}

$D$. Pregunta 1. ¿A qué nos referimos con los términos Anisotropía y Restricción a la Difusión?

La estructura interna de los nervios periféricoscompuesta por mielina, endoneuro, perineuro y epineuro- determina la existencia de múltiples barreras biológicas que facilitan el movimiento de las moléculas de agua en el eje largo del nervio y restringen su difusión en el eje perpendicular (eje corto), característica denominada anisotropía. El nervio patológico presenta pérdida de la anisotropía y alteraciones en el grado de restricción a la difusión (Figura $8 \mathrm{E}$ ).

Esta es la base de técnicas de RM funcional como difusión (DWI) e imágenes con tensor de difusión (DTI), las cuales aportan información cualitativa y cuantitativa respecto a la integridad de la estructura nerviosa, mielina y conducción axonal.
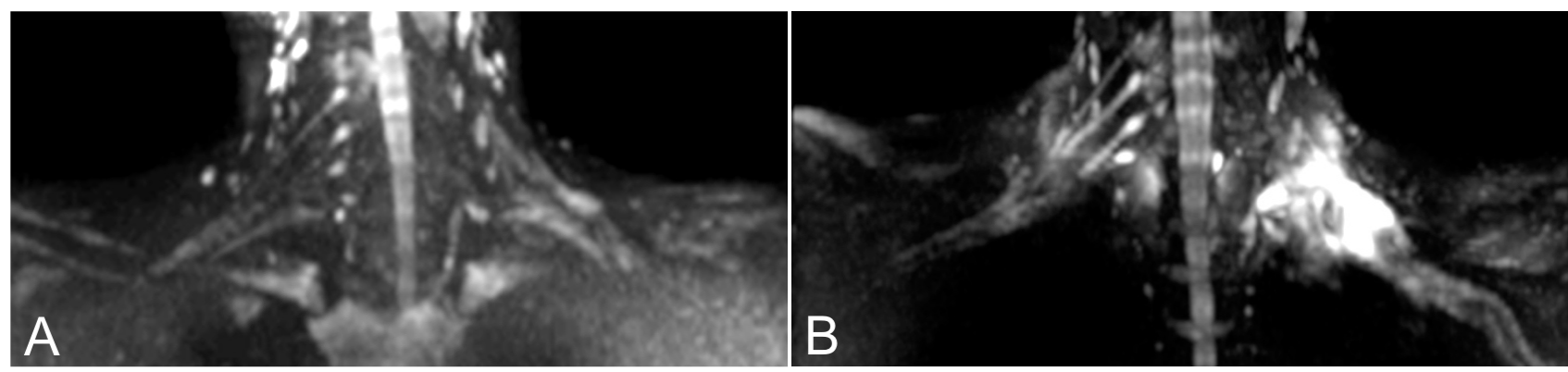

Figura 6: Mismo paciente con avulsión traumática completa del plexo braquial izquierdo. DWI con reconstrucción MIP coronal en resonador 1,5 T (A) y $3 T(B)$. En (B) hay mejor representación de segmentos distales del plexo braquial izquierdo como también de las raíces nerviosas contralaterales.
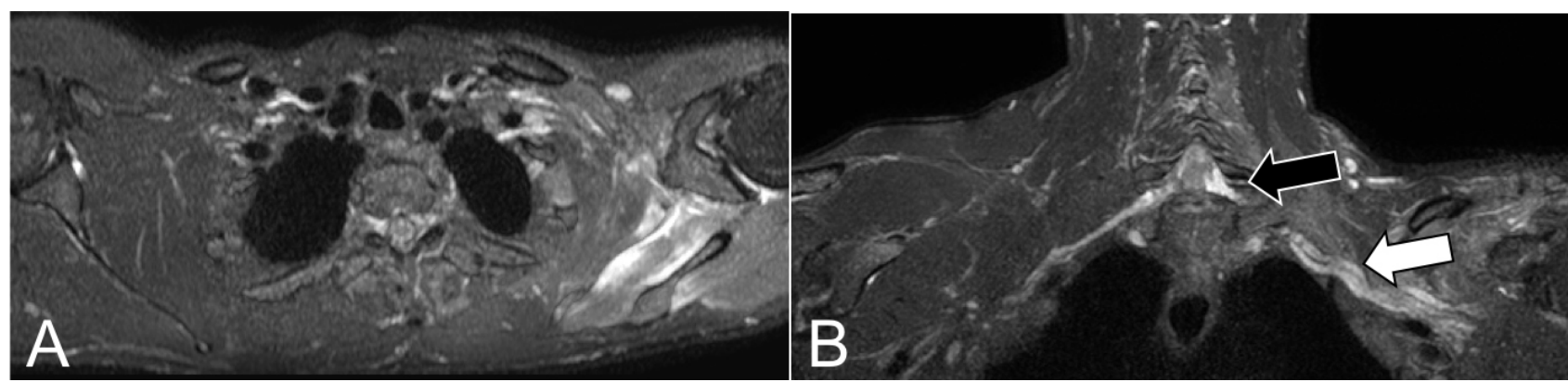

Figura 7: Dos pacientes con lesión de plexo braquial izquierdo. El uso de FOV amplio permite comparar asimetrías en morfología y señal de los nervios y entorno del lado sintomático con el asintomático. (A) STIR axial se observa edema muscular en infraespinoso y subescapular izquierdos, compatible con miopatía por denervación. (B) STIR coronal muestra engrosamiento e hiperseñal del segmento distal del plexobraquial izquierdo (flecha blanca) y pseudomeningocele (flecha negra) por avulsión de la raíz C8 izquierda. 
D. Pregunta 2a. ¿Qué es la Neurografía por difusión?

La restricción a la difusión en el eje perpendicular de los nervios se traduce en alta señal en imágenes DWI (Figura 8A y 8B). Esta cualidad permite resaltar al nervio, especialmente cuando se usan gradientes de difusión de gran magnitud, pues se mantiene la alta señal del nervio mientras se reduce la del entorno ${ }^{24}$. Habitualmente se realiza DWI con valor b de $800 \mathrm{~s} / \mathrm{mm}^{2}$, que otorga relativa buena SNR y adecuada supresión del tejido adyacente. El uso de técnicas de supresión grasa, ya sea espectral (Fat Sat) o no espectral (STIR), aumenta el contraste con las estructuras del fondo ${ }^{25}$. La secuencia de lectura más usada es SS-EPI (Single-shot echo-planar imaging), por lo que tienen sensibilidad al movimiento y artefactos de inhomogeneidad.

El resultado es una imagen selectiva al nervio que permite análisis morfológico, con capacidad de reconstrucción multiplanar y proyección de máxima intensidad (MIP).

\section{Pregunta 2b. ¿Qué podemos ver con DWI?}

Con difusión es posible visualizar la médula espinal, ganglios nerviosos, nervio postganglionar y nervios periféricos ${ }^{26}$. En plexo braquial tiene mala representación de nervios en el segmento preganglionar y por encima de C5 porque las raíces son muy pequeñas, así como también en pacientes con linfonodos grandes porque estas estructuras también restringen a la difusión (Figura 9). Otras limitantes son baja resolución espacial y baja SNR, además de susceptibilidad a inhomogeneidades locales, artefactos de movimiento y pulsación, más pronunciados cercano a los ápices pulmonares, con deglución y pulsación del líquido cefaloraquídeo ${ }^{27}$.

\section{Pregunta 3. Concepto de coeficiente de difusión} aparente $(A D C)$. ¿Qué significan sus resultados?

En secuencias DWI es posible obtener información cuantitativa a través del coeficiente de difusión Aparente (ADC), el cual refleja el desplazamiento de las moléculas de agua en el espacio extracelular sin tener en cuenta la dirección del movimiento. Para calcularlo es necesario agregar una adquisición DWI con bajo valor b (0-50 s/mm²). ADC es el resultado de la diferencia de intensidad de señal entre los valores $b$ bajos y altos, y se expresa en $\mathrm{mm}^{2} / \mathrm{s}^{28}$. Los nervios presentan baja señal en mapas ADC porque presentan restricción a la difusión en el eje corto. Altos valores ADC traducen aumento del espacio extracelular, que generalmente corresponde a edema sea cual sea su origen (trauma, compresión, rotura de fibras, etc) ${ }^{29}$. EI ADC permite cuantificar y monitorizar el edema en nervios periféricos y plexo. Valores ADC bajos son raros, reflejan disminución del espacio extracelular como puede ocurrir en tumores neurogénicos malignos $^{30}$. Respecto a esto último, es importante señalar que puede haber superposición entre los valores ADC para algunas lesiones benignas y malignas ${ }^{31}$, y que su resultado debe ser interpretado considerando otros signos morfológicos de la NRM.

\section{Sección E. Concepto de imágenes con tensor de difusión (DTI) \\ E. Pregunta 1a. ¿En qué consisten las imágenes con DTI? \\ DTI puede considerarse una técnica mejorada de} DWI que permite cuantificar la anisotropía del movimiento de difusión en cada pixel y detectar si hay una dirección preferencial de movimiento. Esto nos permite representar la trayectoria y microestructura de fibras nerviosas basada en la forma en que restringen a la difusión. Para determinar la trayectoria de difusión de las moléculas de agua se necesitan al menos 6 gradientes en diferentes direcciones ${ }^{32}$, pero se recomienda 6 a 16 direcciones con 3 momentos de difusión (valor b: 0,800 y $\left.1.000 \mathrm{~s} / \mathrm{mm}^{2}\right)^{33}$ (Figura 8C y 8D).

Luego de un procesamiento matemático es posible obtener las tres direcciones principales de difusividad en un píxel dado, que corresponde a la dirección dominante (vector principal) y las otras dos direcciones perpendiculares a ella (vectores secundarios). Con estos vectores es posible obtener varios parámetros cuantitativos que pueden ser útiles como biomarcadores, tales como Fracción de Anisotropía (FA), Difusividad Media (MD), Difusividad axial (AD) y Difusividad Radial (RD) ${ }^{28}$.

E. Pregunta 1b. El parámetro cuantitativo más importante del DTI es la fracción de anisotropía (FA). ¿Qué debemos tener en cuenta para interpretar sus resultados?

FA indica el grado de organización de las fibras, con un rango que va desde 0 (mínima anisotropía) a 1 (máxima anisotropía), siendo habitualmente 0,6 en nervios periféricos normales ${ }^{32}$. La FA es un índice sensible, disminuye en casi todas las neuropatías primarias o secundarias ${ }^{34}$. Hasta ahora no existen valores establecidos de FA en neuropatía, además sus valores pueden variar entre distintos nervios y según los parámetros técnicos usados. Por ello los valores de referencias deben ser obtenidos de segmentos de nervio normal en la misma adquisición o comparando con el nervio contralateral (Figura 10A).

FA además permite reconstrucciones neurográficas 3D o tractografías (Figura 10B). Es importante señalar que las fibras visibles en la tractografía no son anatómicamente idénticas a los fascículos individuales, sino que corresponden en términos físicos a líneas de difusión rápida y que éstas habitualmente reflejan la arquitectura axonal ${ }^{35}$. Un potencial error de las reconstrucciones DTI es que el software puede dibujar fibras falsas que no corresponden a estructuras anatómicas, por lo cual el conocimiento de la anatomía del plexo es esencial. El tamaño del 

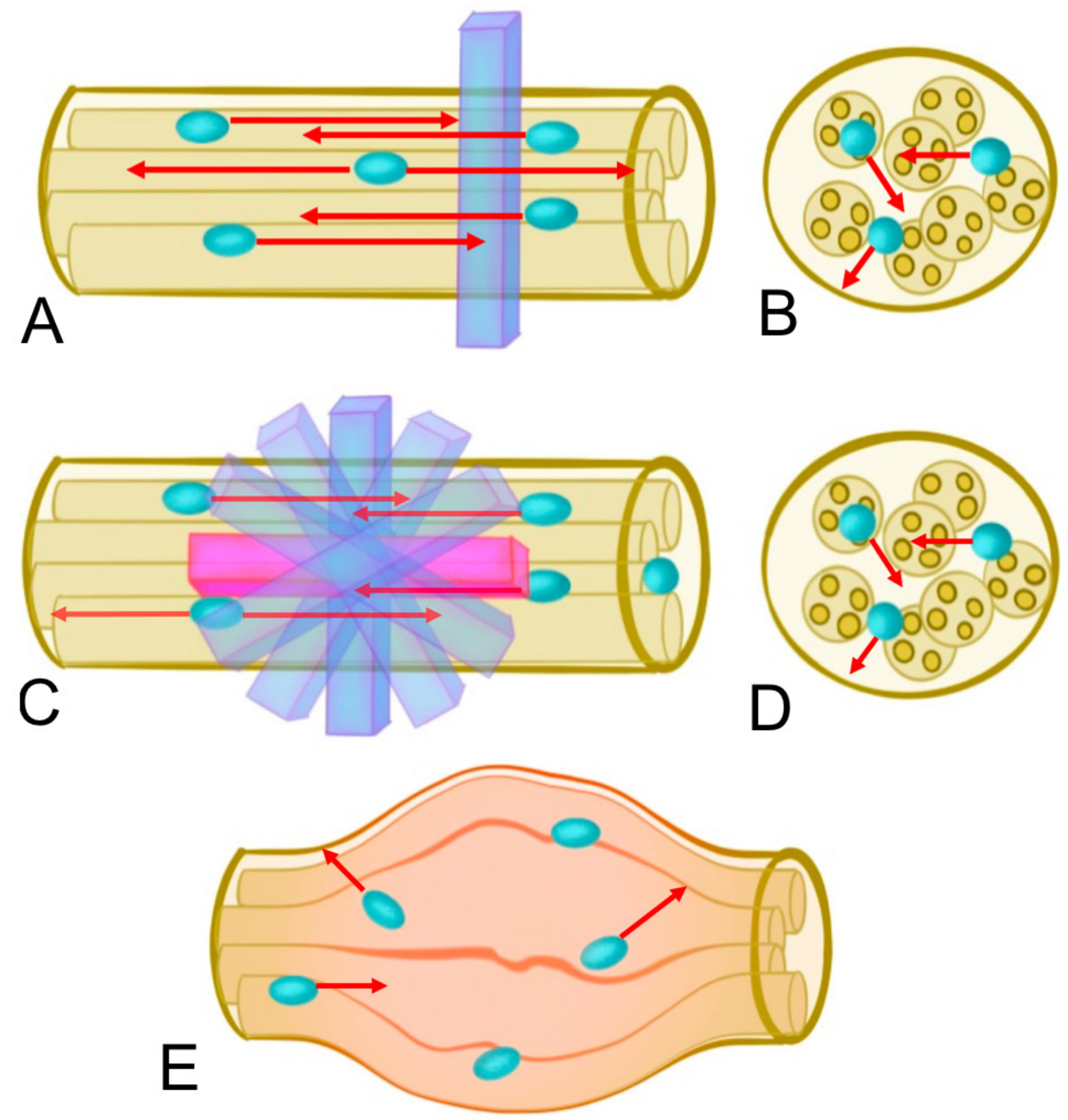

Figura 8: Restricción a la difusión dentro del nervio periférico. (A) y (B) DWI. La difusividad de las moléculas de agua es facilitada a lo largo del eje principal (longitudinal) del nervio. Si los gradientes de movimiento son aplicados perpendicular al nervio, DWI mostrará restricción a la difusión de las moléculas de agua en el eje corto debido a la presencia de barreras fisiológicas, como la vaina de mielina. (C) y (D) DTI. El uso de gradientes en múltiples direcciones (al menos 6) permite evaluar la dirección principal de difusión de las moléculas de agua, con altos valores de FA gracias a la organización propia de las fibras y bajos valores $R D$ debido a la presencia de barreras fisiológicas que limitan la difusión en el plano perpendicular. (E) El daño nervioso, con pérdida de organización de las fibras y aumento del espacio extracelular, se traduce en disminución de los valores de FA y ausencia de una dirección en el movimiento de las moléculas de agua. 


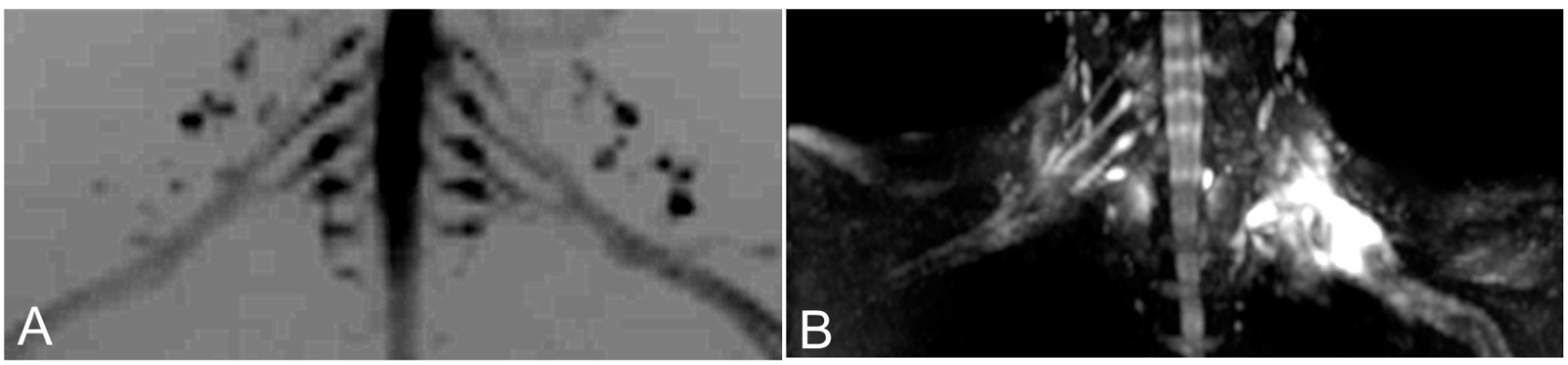

Figura 9: (A) DWI de plexo braquial en voluntario sano con reconstrucción MIP coronal, muestra raíces C5-T1. Raíces por sobre C5 son muy pequeñas para ser representadas. Los linfonodos también presentan restricción a la difusión. (B) DWI en avulsión traumática del plexo braquial izquierdo por accidente en motocicleta. Se observa discontinuidad de todas las raíces nerviosas. Los segmentos distales del plexo presentan marcado engrosamiento y aumento de señal.
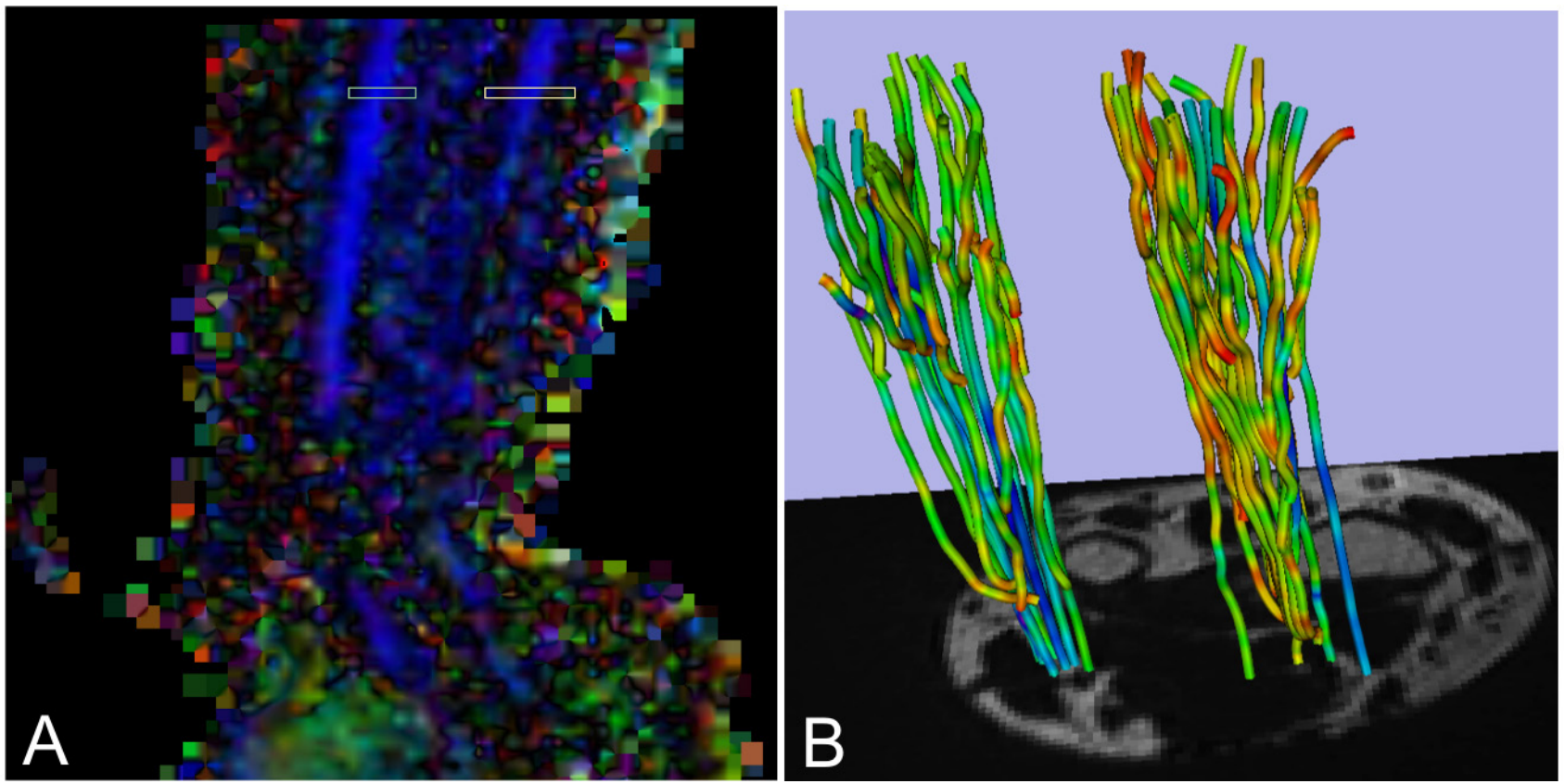

Figura 10: (A) Mapa FA de nervio mediano y cubital en antebrazo distal de voluntario sano, con valor 0,6 dentro de límite normal para nervio periférico. (B) DTI permite realizar reconstrucción neurográfica $3 D$ (tractografía), que muestra dos estructuras fibrilares bien delimitadas en el aspecto anterior del antebrazo. Las fibras visibles en la tractografía no son anatómicamente idénticas a los fascículos individuales, sino que corresponden a líneas de difusión rápida y que éstas habitualmente reflejan la arquitectura axonal. 
vóxel de la mayoría de las secuencias DTI es $2 \times 2$ $x 2 \mathrm{~mm}^{3}$, por lo que son inevitables los efectos de volumen parcial dado el pequeño tamaño del nervio.

E. Pregunta 1C. ¿En términos generales que implican los parámetros difusividad media (MD), Difusividad axial $(A D)$ y difusividad radial $(R D)$ ?

$M D$ indica el desplazamiento de las moléculas de agua en el espacio extracelular, con un significado similar a ADC, pero más preciso por el uso de múltiples direcciones de difusión ${ }^{36}$.

$A D$ indica el movimiento del agua a lo largo de la dirección principal del nervio, también llamado flujo axonal.

$\mathrm{RD}$ indica el grado de restricción a la difusión del agua en el plano perpendicular al eje principal. Está muy relacionado a la integridad de la vaina de mielina y ha sido considerado como el parámetro más específico derivado del DTI para la evaluación del nervio periférico ${ }^{28}$. RD es siempre menor que $A D$.

E. Pregunta 2. ¿Actualmente cuál es la utilidad clínica de secuencias DWI y DTI?

Las técnicas funcionales han demostrado utilidad en estudio de plexo braquial, detección de lesiones neoplásicas y planificación prequirúrgica ${ }^{35}$.

DWI es una técnica rápida que permite visualizar en forma simple todo el nervio con un postproceso sencillo. Permite confirmar, descartar o detectar (sospechada o no) la neuropatía.

DTI otorga información única respecto a los nervios, sin embargo, consume mucho más tiempo tanto en la adquisición de las imágenes como en el postproceso. Además, los valores de los diferentes parámetros pueden variar por múltiples factores, como el tipo de resonador, teslaje e incluso por el protocolo usado ${ }^{28}$. Por ello, la integración como secuencia de rutina en todos los protocolos de NRM aún no es generalizada y todavía se requieren más estudios para estandarizar el diseño de las secuencias y establecer valores normales para cada parámetro.

\section{Sección F: Paquete neurovascular. ¿Cómo suprimir la señal de la grasa y vasos sanguíneos perineurales?}

F. Pregunta 1a. ¿Cómo afecta la señal de la grasa en la visualización del nervio dentro del paquete neurovascular?

Con su tiempo de relajación $\mathrm{T} 1$ relativamente corto, la grasa a menudo presenta hiperseñal en muchas secuencias importantes y puede oscurecer algunas patologías como edema, inflamación o tumores. Por ello se utilizan métodos para eliminar la señal de la grasa y mejorar la visualización de estas anormalidades ${ }^{37}$. La supresión de la grasa tiene el beneficio adicional de eliminar artefactos de desplazamiento químico dado que la señal de la grasa ya no se encuentra presente, y menores anchos de banda son necesarios para mejorar la relación señal-ruido $(\mathrm{SNR})^{38}$.

\section{F. Pregunta 1b. ¿Qué técnicas existen para sa-} turar la grasa?

En RM los protones en las moléculas de grasa y agua presentan diferentes peaks de frecuencias de precesión, con separación de $210-220 \mathrm{~Hz}$ en resonador de $1,5 \mathrm{~T}$ y $420-440 \mathrm{~Hz}$ en $3 \mathrm{~T}^{38}$. Esta natural separación es utilizada para saturar la señal de la grasa.

Existen varias técnicas de supresión grasa y separación agua-grasa. Analizar sus ventajas y desventajas permite entender por qué algunos métodos funcionan mejor que otros en aplicaciones clínicas diferentes.

Saturación espectral o por selección de frecuencia (Fat Sat, FS): Se aplica un pulso corto de RF centrado al peak de frecuencia de la grasa, estimulando sólo estos protones, el cual es seguido por gradientes spoiler que desfasan la señal de la grasa. Después, al realizar una secuencia de lectura estándar (TSE, GRE, etc.), los protones saturados de la grasa no generan señal, resultando en una imagen con señal solo desde los protones de agua ${ }^{38}$.

Es el método más usado en resonadores de alto y bajo teslaje, de especial utilidad en el estudio de extremidades. No deben ser usadas si hay un elemento metálico en el FOV. Sus desventajas incluyen sensibilidad a heterogeneidades de campo magnético, mala supresión en áreas lejos del isocentro del magneto y supresión poco homogénea especialmente a lo largo de las curvas de las extremidades ${ }^{37}$.

Excitación selectiva del agua: Técnica por saturación espectral en que se excita el peak de agua directamente, en vez de suprimir el de grasa. Tiene relativamente alta SNR e insensibilidad a la heterogeneidad de campo $B_{1}{ }^{37}$. Es sensible a inhomogeneidades del campo magnético principal $\left(\mathrm{B}_{0}\right)^{33}$.

Saturación con tiempo de inversión (STIR," recuperación de inversión con tiempo de inversión corto"): Consiste en preparar la magnetización antes de la secuencia de lectura (TSE o GRE) con un pulso adicional de inversión de $180^{\circ}$. El período de tiempo entre el pulso de RF de $180^{\circ}$ y el pulso de excitación de la secuencia de lectura se llama tiempo de inversión (TI). En imágenes con pulso de inversión recuperación (IR), la intensidad de señal de cualquier tejido puede ser anulada por variaciones en el tiempo de inversión (TI). Escogiendo un TI corto (STIR), se suprime la señal del tejido con T1 corto, como el de la grasa.

Entre sus ventajas destaca la excelente y homogénea saturación grasa incluso en zonas anatómicas fueras del isocentro (codo, mano, muñeca) o en áreas con muchas interfaces aire-tejido (plexo braquial, dedos, pie). El pulso de IR hace que sea insensible a cambios de homogeneidad de campo con objetos metálicos. Es útil cuando el FOV es grande (plexo braquial y lumbosacro) ${ }^{37}$. 
Sus desventajas son los frecuentes artefactos de pulsación, baja relación señal-ruido, aumento artefactual de la señal del nervio y tiempos de adquisición más largos. En caso de usarla se recomiendan algunas modificaciones, como disminuir el TE (30-40 ms) para mantener buena SNR, aumentar el ETL y ancho de banda. Es importante destacar que STIR genera una supresión de grasa no selectiva, es decir suprime la señal de la grasa al igual que otros tejidos que también posean valores T1 cortos. Por lo cual STIR "oculta" el realce con gadolinio, pues los tejidos con gadolinio acortan su valor $\mathrm{T} 1$ a un rango similar a la grasa ${ }^{39}$.

DIXON: Descrito inicialmente con técnica de 2 puntos, corresponde a un método de separación agua-grasa basado en el desplazamiento químico ${ }^{40}$. Tras la adquisición simultánea de imágenes en fase y fuera de fase, se realiza un postproceso de adición y sustracción de éstas, obteniendo además imágenes de "sólo agua" y "sólo grasa". El método Dixon ha sido mejorado con técnicas de 3 o más puntos, en diferentes esquemas y algoritmos según el proveedor. Genera una supresión grasa firme y homogénea sin pérdida de señal ni disminución de SNR, y dado que es insensible a heterogeneidades del campo magnético es posible utilizarla cuando hay implantes metálicos o en zonas anatómicas difíciles ${ }^{41}$. Es posible aplicarla en imágenes $2 \mathrm{D}$ y $3 \mathrm{D}$ con diferentes pulsos de secuencia tales como spin-eco (T1, T2 y DP) y ecogradientes. Sus principales desventajas son el mayor tiempo de adquisición y en zonas muy inhomogéneas la posibilidad del artefacto "intercambio agua-grasa" en el que se produce una imagen de "solo grasa" cuando se deseaba una imagen "sólo agua", artefacto que disminuye con la técnica de 3 puntos.

F. Pregunta 2a. ¿Existen técnicas para disminuir la señal de los vasos dentro del paquete neurovascular?

Uno de los principales obstáculos en la NRM es la alta señal de los vasos en el paquete neurovascular, lo que afecta la relación contraste/ruido y puede limitar la visualización precisa del nervio. Es posible co-aplicar técnicas de supresión de la señal vascular, que consisten en pulsos de preparación que suprimen la señal del flujo sanguíneo mientras mantienen alta la señal en los tejidos estacionarios circundantes, que tiene como ventaja adicional eliminar el artefacto de pulsación de las arterias (Figura 11). Si bien son un excelente método de supresión para vasos de alto flujo, son menos efectivas para las pequeñas venas con flujo lento, las cuales pueden persistir con alta señal y ser malinterpretadas como pequeñas ramas nerviosas o edema perineural. Otras desventajas incluyen aumento del tiempo de adquisición y mayor susceptibilidad a heterogeneidades del campo magnético.

Otra alternativa es la inyección de gadolinio previo a la secuencia STIR, que recientemente ha demostrado buenos resultados en el estudio de plexo braquial ${ }^{42}$ y lumbosacro ${ }^{43}$.
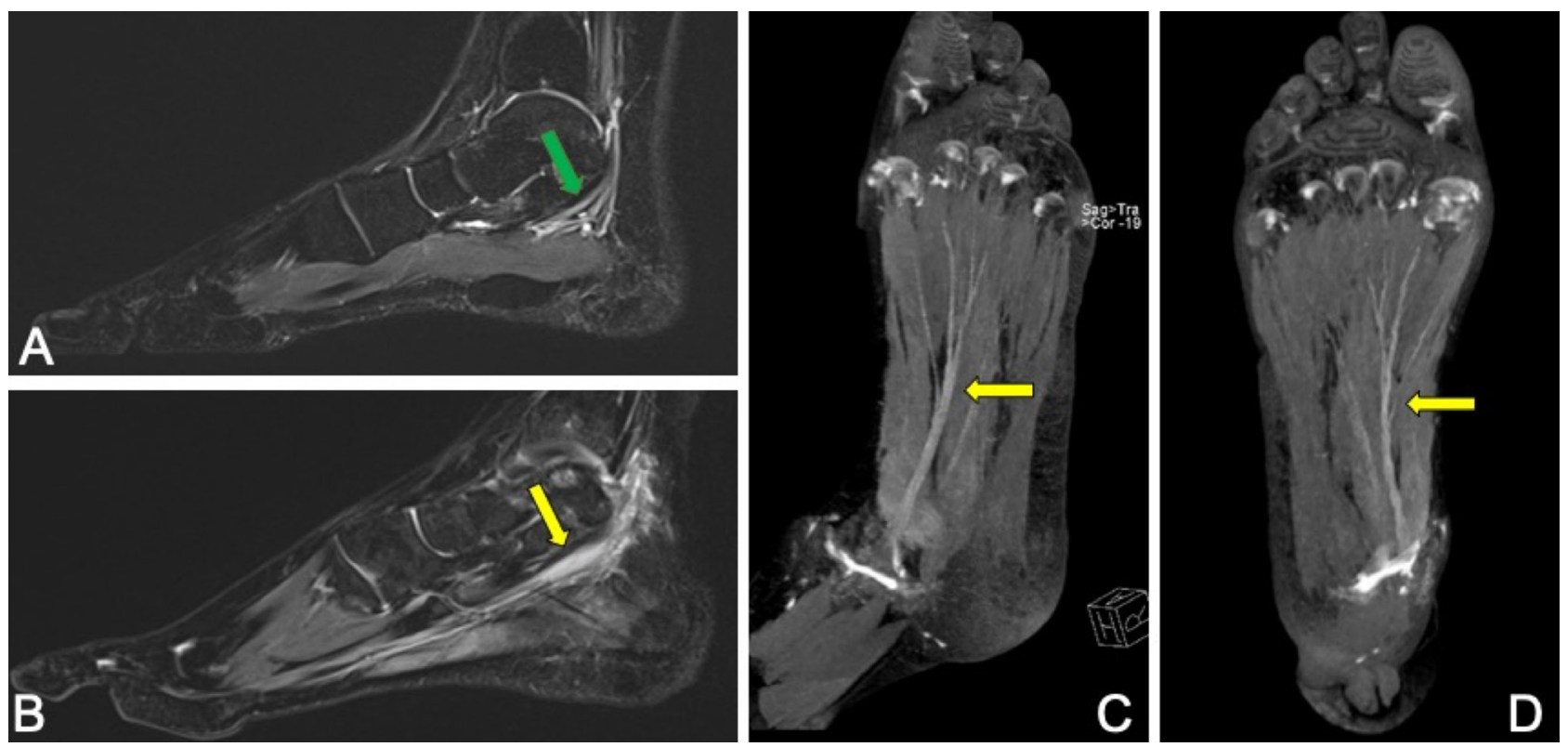

Figura 11: (A) STIR sagital del tobillo derecho preoperatoria en paciente con pinzamiento posterior, muestra nervio tibial posterior normal (flecha verde). (B) STIR sagital postoperatoria, el paciente evoluciona con neuropatía del nervio tibial posterior, el cual se observa engrosado y con aumento de señal (flecha amarilla). (C) y (D) 3D STIR MIP con supresión de flujo permite una mejor visualización del engrosamiento de la rama plantar medial del nervio, sin la interposición de los vasos sanguíneos. 
F. Pregunta 2b. ¿En qué consiste la supresión de vasos sanguíneos con Gadolinio y STIR?

Como se mencionó previamente, STIR oculta el realce de los tejidos con gadolinio, lo que se traduce en supresión de arterias, venas y linfonodos. La barrera hematoneural impide el paso de gadolinio al nervio, razón por la cual su intensidad de señal no se afecta significativamente ${ }^{42}$. Es posible utilizarlo con secuencias 2D o 3D. La secuencia 3D STIR post contraste tiene mejor relación contraste-ruido entre los nervios y las partes blandas adyacentes que 3D STIR sin contraste $^{42,43}$ (Figuras 12 y 13). Es fundamental tener presente que el uso de gadolinio podría ocultar otras lesiones fácilmente visibles en STIR, como por ejemplo tumores óseos, por lo que no se debe reemplazar una adquisición previa STIR sin contraste.

\section{Sección G. Pitfalls y Artefactos}

G. Pregunta 1. La NRM es susceptible a artefactos y pitfalls que pueden determinar errores diagnósticos. ¿Cuáles son los principales?, ¿Cómo podemos evitarlos?

Efecto de ángulo mágico: Artefacto que puede simular hiperintensidad de señal T2 en un nervio periférico normal cuando se obtienen imágenes en un plano superior a $55^{\circ}$ respecto al campo magnético principal. A diferencia de los tendones, el artefacto en los nervios puede persistir con TE mayor a 66 ms y, por lo tanto, mayores TE deben ser usados (recomendado 90-130 ms) ${ }^{44}$. Es más frecuente en nervios de trayecto oblicuo, como nervio ciático en la escotadura ciática mayor, nervios femorales en la pelvis, nervio plantar medial en el retropié o nervio peroneo común en la fosa poplitea ${ }^{45}$. Este artefacto
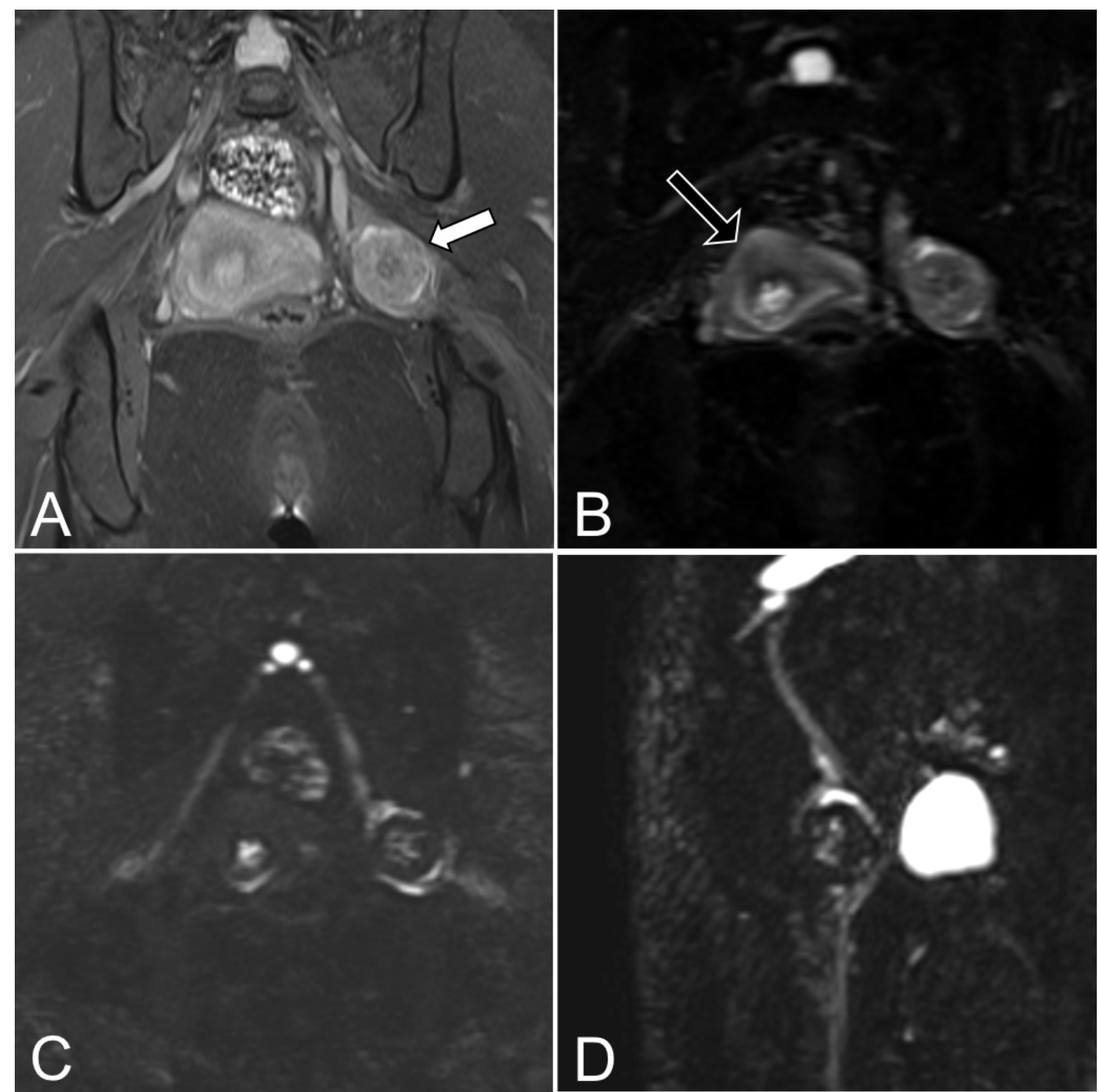

Figura 12: Plexo lumbosacro. Tumor de vaina nerviosa de la raíz S2 izquierda. (A) T1 Coronal post gadolinio muestra realce del tumor (flecha blanca) debido a la alteración en la barrera hematoneural. (B) En STIR coronal pre gadolinio la lesión presenta hiperseñal al igual que el útero (flecha negra). (C) STIR coronal isotrópico post gadolinio suprime la señal de estructuras vasculares y órganos pelvianos, con un mejor contraste y demostración de la ubicación de la lesión. (D) STIR isotrópico post gadolinio con reconstrucción curva de la raíz S2 izquierda. El tumor también presenta caída de señal. 

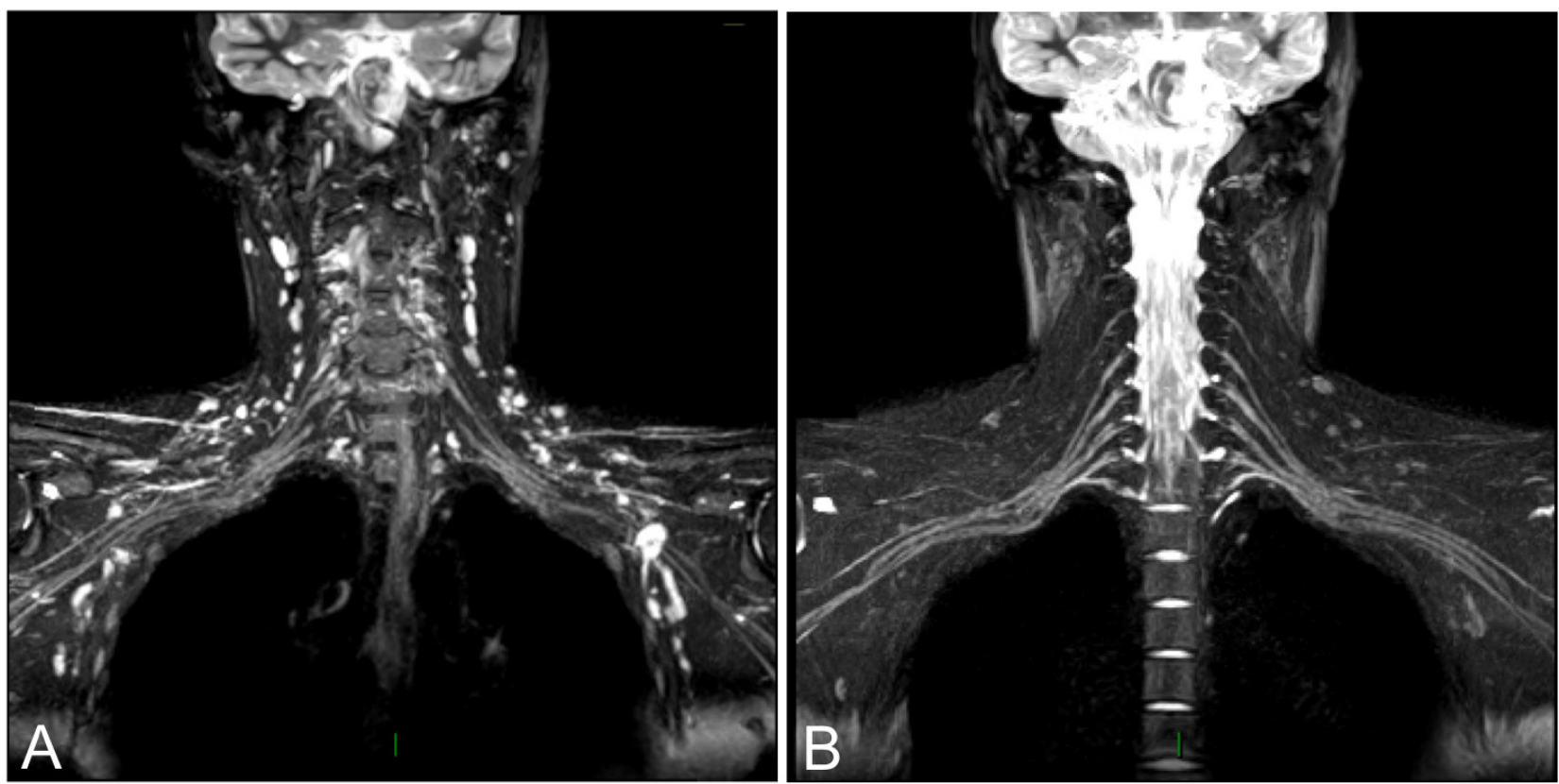

Figura 13: (A) 3D STIR pre gadolinio reconstrucción MIP y (B) 3D STIR post gadolinio reconstrucción MIP. En (A) debido a la señal del paquete vascular, no son claros los límites entre el plexo braquial, las venas y linfonodos adyacentes. En (B) las señales que rodean las venas y linfonodos disminuyen y el efecto de supresión grasa es mejor.

es bilateral y simétrico por la constante posición de los nervios. Una comparación detallada en busca de asimetrías de señal, presencia de otros signos como alteración focal del contorno, desplazamiento o signos de denervación son importantes para un diagnóstico preciso.

Denervación versus Miositis o Miopatía: En el músculo denervado los hallazgos son difusos en el área regional del nervio ${ }^{5}$, no se asocian a edema ni realce de la fascia como tampoco a edema subcutáneo, a diferencia de la miositis infecciosa o desgarros ${ }^{10}$. Miopatías son frecuentemente bilaterales y pueden comprometer múltiples compartimentos.

Variantes anatómicas: Como músculos accesorios o variación en la relación espacial del nervio respecto a las estructuras vecinas, lo cual además puede predisponer a atrapamiento.

Aumento de señal vascular: En el paquete vasculonervioso las arterias presentan vacío de señal y las venas alta señal por el fenómeno inflow, que algunas veces puede persistir incluso después de pulsos de radiofrecuencia supresivos, especialmente con TE alto.

Supresión grasa inhomogénea: Especialmente en la pelvis por el gran FOV y el uso de prótesis cada vez más frecuente. Es fundamental una buena técnica de supresión grasa y un FOV adecuado para controlar el tiempo de adquisición ${ }^{40}$.

Artefacto de susceptibilidad y desplazamiento químico: Ambos artefactos son más pronunciados en resonador $3 \mathrm{~T}$, lo cual se puede reducir al acortar el TE, realizar técnicas paralelas e incrementar el ancho de banda ${ }^{27}$.

\section{Conclusiones}

La NRM es un estudio demandante que requiere el conocimiento de las principales preguntas clínicas, la anatomía del nervio periférico y entorno perineural, así como también de las técnicas de imagen disponibles.

En los últimos años han aumentado las secuencias selectivas al nervio. Cada una de estas herramientas tiene requisitos técnicos y artefactos específicos que deben ser conocidos para evitar errores diagnósticos.

La utilización de técnicas funcionales, como difusión (DWI) e imágenes con tensor de difusión (DTI), ofrecen parámetros adicionales para la evaluación de nervios periféricos, pero no reemplazan el análisis morfológico, el cual sigue siendo la base del diagnóstico por imágenes en neuropatías.

\section{Referencias}

1. Feinberg J. EMG: Myths and Facts. HSS J. 2006; 2(1): 19-21. doi: 10.1007/s11420-005-0124-0

2. Cejas AC. Neurografía por resonancia magnética en la evaluación de los nervios periféricos. Rev Chil Radiol. 2015; 21(3): 108-115. doi: 10.4067/S071793082015000300006

3. Andreisek G, Burg D, Studer A, Weishaupt D. Upper extremity peripheral neuropathies: Role and impact of MR imaging on patient management. Eur Radiol. 2008; 18(9): 1953-1961. doi: 10.1007/s00330-008-0940-y

4. Kim S, Choi JY, Huh YM, et al. Role of magnetic reso- 
nance imaging in entrapment and compressive neuropathy - What, where, and how to see the peripheral nerves on the musculoskeletal magnetic resonance image: Part 2. Upper extremity. Eur Radiol. 2007; 17(2): 509-522. doi: 10.1007/s00330-006-0180-y

5. Kim SJ, Hong SH, Jun WS, et al. MR imaging mapping of skeletal muscle denervation in entrapment and compressive neuropathies. RadioGraphics. 2011; 31(2): 319-332. doi: 10.1148/rg.312105122

6. Chin CT. Magnetic resonance neurography. Nerve Vasc Inj Sport Med. 2009: 27-39. doi: 10.1007/978-0387-76600-3_3

7. Reinhold A, Rittner $\mathrm{H}$. Barrier function in the peripheral and central nervous system-a review. Pflugers Arch Eur J Physiol. 2017; 469(1): 123-134. doi:10.1007/s00424016-1920-8

8. Zhou L, Yousem DM, Chaudhry V. Role of magnetic resonance neurography in brachial plexus lesions. Muscle and Nerve. 2004; 30(3): 305-309. doi: 10.1002/ mus.20108

9. Carpenter EL, Bencardino JT. Focus on advanced magnetic resonance techniques in clinical practice: Magnetic Resonance Neurography. Radiol Clin North Am. 2015; 53(3): 513-529. doi: 10.1016/j.rcl.2014.12.002

10. Smitaman E, Flores DV, Mejía Gómez C, Pathria MN. MR imaging of atraumatic muscle disorders. Radiographics. 2018; 38(2): 500-522. doi: 10.1148/rg.2017170112

11. May DA, Disler DG, Jones EA, Balkissoon AA, Manaster BJ. Abnormal signal intensity in skeletal muscle at MR imaging: Patterns, pearls, and pitfalls. Radiographics. 2000; 20(SPEC.ISS.): 295-315. doi: 10.1148/radiographics.20.suppl_1.g00oc18s295

12. Deroide N, Bousson V, Mambre L, Vicaut E, Laredo JD, Kubis N. Muscle MRI STIR signal intensity and atrophy are correlated to focal lower limb neuropathy severity. Eur Radiol. 2015; 25(3): 644-651. doi: 10.1007/ s00330-014-3436-y

13. Gilcrease-Garcia BM, Deshmukh SD, Parsons MS. Anatomy, imaging, and pathologic conditions of the brachial plexus. Radiographics. 2020; 40(6): 1686-1714. doi: 10.1148/rg.2020200012

14. Bowen BC, Pattany PM, Saraf-Lavi E, Maravilla KR. The brachial plexus: Normal anatomy, pathology, and MR imaging. Neuroimaging Clin N Am. 2004; 14(1): 59-85. doi: 10.1016/j.nic.2003.12.002

15. Viallon M, Vargas MI, Jlassi $\mathrm{H}$, Lövblad KO, Delavelle J. High-resolution and functional magnetic resonance imaging of the brachial plexus using an isotropic 3D T2 STIR (Short Term Inversion Recovery) SPACE sequence and diffusion tensor imaging. Eur Radiol. 2008; 18(5): 1018-1023. doi: 10.1007/s00330-007-0834-4

16. Vargas MI, Gariani J, Delattre BA, Dietemann JL, Lovblad K, Becker M. Three-dimensional MR imaging of the brachial plexus. Semin Musculoskelet Radiol. 2015 Apr; 19(2): 137-148. doi: 10.1055/s-0035-1546300

17. Mugler JP. Optimized three-dimensional fast-spin-echo MRI. J Magn Reson Imaging. 2014; 39(4): 745-767. doi: 10.1002/jmri.24542

18. Li Z, Chen YA, Chow D, Talbott J, Glastonbury C, Shah V. Practical applications of CISS MRI in spine imaging. Eur J Radiol Open. 2019 june; 6: 231-242. doi: 10.1016/j. ejro.2019.06.001

19. Wade RG, Takwoingi Y, Wormald JCR, et al. MRI for detecting root avulsions in traumatic adult brachial plexus injuries: A systematic review and meta-analysis of diagnostic accuracy. Radiology. 2019; 29: 190-218. doi: 10.1148/radiol.2019190218

20. Kuo R, Panchal M, Tanenbaum L, Crues JV. 3.0 Tesla imaging of the musculoskeletal system. J Magn Reson Imaging. 2007; 25(2): 245-261. doi:10.1002/jmri.20815

21. Chang KJ, Kamel IR, Macura KJ, Bluemke DA. 3.0-T MR imaging of the Abdomen: Comparison with 1.5 T. Radiographics. 2008; 28(7): 1983-1998. doi: 10.1148/ rg. 287075154

22. Andreisek G, Bolog NV. Getting started with magnetic resonance neurography. Semin Musculoskelet Radiol. 2018; 22(3): 334-343. doi: 10.1055/s-0038-1641576

23. Chalian M, Chhabra A. Top-10 Tips for Getting Started with magnetic resonance neurography. Semin Musculoskelet Radiol. 2019; 23(4): 347-360. doi: 10.1055/s0039-1677727

24. Takahara T, Hendrikse J, Kwee TC, et al. Diffusionweighted MR neurography of the sacral plexus with unidirectional motion probing gradients. Eur Radiol. 2010; 20(5): 1221-1226. doi: 10.1007/s00330-009-1665-2

25. Kwee TC, Takahara T, Niwa T, et al. Improving background suppression in diffusion-weighted imaging of the abdomen and pelvis using STIR with single-axis diffusion encoding. Magn Reson Imaging. 2011; 29(6): 877-880. doi: 10.1016/j.mri.2011.02.029

26. Vargas MI, Viallon M, Nguyen D, Beaulieu JY, Delavelle J, Becker M. New approaches in imaging of the brachial plexus. Eur J Radiol. 2010; 74(2): 403-410. doi: 10.1016/j.ejrad.2010.01.024

27. Chhabra A, Lee PP, Bizzell C, Soldatos T. 3 Tesla MR neurography-Technique, interpretation, and pitfalls. Skeletal Radiol. 2011; 40(10): 1249-1260. doi: 10.1007/ s00256-011-1183-6

28. Noguerol TM, Barousse R, Cabrera MG, Socolovsky M, Bencardino JT, Luna A. Functional MR neurography in evaluation of peripheral nerve trauma and postsurgical assessment. Radiographics. 2019; 39(2): 427-446. doi: 10.1148/rg.2019180112

29. Eguchi Y, Ohtori S, Yamashita M, et al. Clinical applications of diffusion magnetic resonance imaging of the lumbar foraminal nerve root entrapment. Eur Spine J. 2010; 19(11): 1874-1882. doi: 10.1007/s00586-010$1520-9$

30. Ahlawat S, Chhabra A, Blakely J. Magnetic resonance neurography of peripheral nerve tumors and tumorlike conditions. Neuroimaging Clin N Am. 2014; 24(1): 171192. doi: 10.1016/j.nic.2013.03.035

31. Einarsdóttir H, Karlsson M, Wejde J, Bauer HCF. Diffusion-weighted MRI of soft tissue tumours. Eur Radiol. 2004; 14(6): 959-963. doi: 10.1007/s00330004-2237-0

32. Mohamed Ail Hassan HGE, Bassiouny RH, Abdelsattar Mohammad S. Quantitative MR neurography of brachial plexus lesions based on diffusivity measurements. Egypt J Radiol Nucl Med. 2018; 49(4): 1093-1102. doi: 10.1016/j.ejrnm.2018.05.005

33. Chhabra A, Flammang A, Padua A, Carrino JA, Andreisek $G$. Magnetic resonance neurography. Technical considerations. Neuroimaging Clin N Am. 2014; 24(1): 67-78. doi: 10.1016/j.nic.2013.03.032

34. Bäumer $P$, Pham $M$, Ruetters $M$, et al. Peripheral 
neuropathy: Detection with diffusion-tensor imaging. Radiology. 2014; 273(1): 185-193. doi: 10.1148/radiol.14132837

35. Vargas MI, Viallon M, Nguyen D, Delavelle J, Becker M. Diffusion tensor imaging (DTI) and tractography of the brachial plexus: Feasibility and initial experience in neoplastic conditions. Neuroradiology. 2010; 52(3): 237-245. doi: 10.1007/s00234-009-0643-3

36. Noguerol TM, Barousse R, Socolovsky M, Luna A. Quantitative magnetic resonance (MR) neurography for evaluation of peripheral nerves and plexus injuries. Quant Imaging Med Surg. 2017; 7(4): 398-421. doi: 10.21037/qims.2017.08.01

37. Grande F Del, Santini F, Herzka DA, et al. Fatsuppression techniques for 3-T MR imaging of the musculoskeletal system. Radiographics. 2014; 34(1): 217-233. doi: 10.1148/rg.341135130

38. Bley TA, Wieben O, François CJ, Brittain JH, Reeder SB. Fat and water magnetic resonance imaging. J Magn Reson Imaging. 2010; 31(1): 4-18. doi: 10.1002/ jmri.21895

39. Krinsky G, Rofsky NM, Weinreb JC. Nonspecificity of short inversion time inversion recovery (STIR) as a technique of fat suppression: Pitfalls in image interpretation. Am J Roentgenol. 1996; 166(3): 523-526. doi: 10.2214/ajr.166.3.8623620

40. Ma J. Dixon techniques for water and fat imaging. J Magn Reson Imaging. 2008; 28(3): 543-558. doi: 10.1002/jmri.21492

41. Kirchgesner T, Perlepe V, Michoux N, Larbi A, Vande Berg B. Fat suppression at 2D MR imaging of the hands: Dixon method versus CHESS technique and STIR sequence. Eur J Radiol. 2017; 89: 40-46. doi: 10.1016/j.ejrad.2017.01.011

42. Chen WC, Tsai YH, Weng HH, et al. Value of enhancement technique in 3D-T2-STIR images of the brachial plexus. J Comput Assist Tomogr. 2014; 38(3): 335-339. doi: 10.1097/RCT.0000000000000061

43. Zhang $Y$, Kong X, Zhao Q, Liu X, Gu Y, Xu L. Enhanced MR neurography of the lumbosacral plexus with robust vascular suppression and improved delineation of its small branches. Eur J Radiol. 2020 January; 129: 109-128. doi: 10.1016/j.ejrad.2020.109128

44. Kästel T, Heiland S, Bäumer P, Bartsch AJ, Bendszus $M$, Pham M. Magic angle effect: A relevant artifact in MR neurography at 3T? Am J Neuroradiol. 2011; 32(5): 821-827. doi :10.3174/ajnr.A2402

45. Chhabra A. Peripheral MR neurography. Approach to interpretation. Neuroimaging Clin N Am. 2014; 24(1): 79-89. doi: 10.1016/j.nic.2013.03.033 